\title{
Electrodeposition of PANI/MWCNT Coatings on Stainless Steel and Their Corrosion Protection Performances
}

\section{Wei $\mathrm{Li}$}

Department of capital construction of Xinxiang University, Xinxiang, Henan, 453000, P.R. China E-mail: weili_1912@163.com

doi: $10.20964 / 2018.02 .31$

Received: 9 September 2017 / Accepted: 19 October 2017 / Published: 28 December 2017

When used under corrosive conditions as a coating material, nanostructured composites demonstrated higher sensitivity and better performance. In this work, mild steel (MS) structures were effectively protected through enhancement of the mechanical and corrosive performances of polyaniline (PANI) coatings using functionalized carbon nanotubes (CNTs). Fourier transform infrared (FTIR) spectroscopy and cyclic voltammetry (CV) were used to measure the coatings. Electrochemical impedance spectroscopy (EIS) and the Tafel test were used to study the corrosion performance of polymer-coated MS configurations in a highly corrosive $0.5 \mathrm{M} \mathrm{HCl}$ solution. For all immersion times, the corrosion resistance of the PANI/MWCNT was found to be higher than that of other coatings.

Keywords: Carbon nanotubes; Polyaniline; Electrodeposition; Corrosion protection; Nanocomposite

\section{$\underline{\text { FULL TEXT }}$}

(C) 2018 The Authors. Published by ESG (www.electrochemsci.org). This article is an open access article distributed under the terms and conditions of the Creative Commons Attribution license (http://creativecommons.org/licenses/by/4.0/). 